\title{
Influence of the Method of Strengthening the Surface of Parts on Acoustic Characteristics
}

\author{
Elena Levashova ${ }^{1 *}$, Nikolai Ababkov ${ }^{1}$, MaksimPimonov ${ }^{1}$ \\ ${ }^{1}$ T.F. Gorbachev Kuzbass State Technical University, Department of Mechanical Engineering, \\ 650000 Kemerovo, 28 Vesennya st., the Russian Federation
}

\begin{abstract}
The article is devoted to the consideration of the method of increasing the mechanical and tribological properties of parts of mining machines due to quenching and electric arc hardening of the restored surface layer by welding. The essence of the proposed method was to restore the geometric dimensions of the part with cored wire with guaranteed hardness of 50-55 HRC and an increase in values up to $60 \mathrm{HRC}$ due to electric arc hardening (EAH), which uses equipment available at each mining enterprise, namely, a tungsten-electrode torch cooled water and protective gas. Argon, which has a relatively low ionization potential, was used as a protective gas, and the use of carbon dioxide was not considered, owing to the increased tendency to crack formation of layers strengthened in this way. The results of studies of the acoustic characteristics of the restored part of the rotation of the welding, made of steel 30HGSA in the initial state of surfacing after electric arc hardening, after quenching and the combined combination of hardening and electric arc hardening are shown.
\end{abstract}

\section{Introduction}

As you know, the main methods for improving mechanical properties and creating a certain structure of restored parts of mining equipment is heat treatment. The most common methods are laser treatment, electrospark doping and surface hardening.

Currently, such methods of surface heat treatment as a plasma arc [1-6], laser treatment $[7,8]$, quenching and heating with a flame with a gas-oxygen torch [9-11] are being studied.

During plasma processing, the hardness value is 2 ... 4 HRC units more compared to the volume quenching and HDTV, as well as wear resistance and fracture resistance. The depth of the hardened layer is about $2.5 \ldots 3.5 \mathrm{~mm}$, but often the rejection sign is wear by $0.5 \ldots$ $0.9 \mathrm{~mm}$, such a depth of the hardened layer complicates the subsequent restoration of the part. The negative aspect of this method is the choice of a plasmatron with a specialized high-voltage rectifier idling $180 \ldots 300 \mathrm{~V}$, the operation of the devices is accompanied by increased exposure to harmful and dangerous production factors (such as arc radiation, aerosols, noise and metallic dust), which requires special protective construction.

\footnotetext{
${ }^{*}$ Corresponding author: petrova.lena-petrova2010@yandex.ru
} 
During laser treatment in the process of exposure to a concentrated flow of energy, a quenching type structure is formed, which has increased strength, hardness and wear resistance. To create a surface layer with such parameters it is necessary to use high-power lasers of continuous radiation, which have a high cost, low efficiency (up to 15\%) and are characterized by high operating costs.

This article is devoted to the consideration of the method of increasing the mechanical and tribological properties of parts of mining machines due to quenching and electric arc hardening of the restored surface layer by welding. The essence of the proposed method is to restore the geometric dimensions of the part powder wire with a guaranteed hardness of 50-55 HRC and an increase in values up to $60 \mathrm{HRC}$ due to electric arc hardening (EAH), in which equipment is used that is available at each mining enterprise, namely a water-cooled tungsten electrode torch and protective gas. Argon, which has a relatively low ionization potential, is used as a protective gas; the use of carbon dioxide is not considered, owing to an increased tendency to crack formation of layers strengthened in this way. In the process of the method, we plan to obtain the structure of residual austenite, which during operation (shock loads and abrasive wear) allows for the energy suppressing process of the deformed martensitic transformation, which will lead to an increase in wear resistance.

The aim of the work is a comparative analysis of metallographic studies and the tribological characteristics of the hardened surface in such ways as, EAH, quenching and the combined effect on the weld layer.

The object of study is the deposited samples in two layers in a protective gas $\left(\mathrm{CO}_{2}\right)$ medium with flux-cored wire 35H5GNFVM on a substrate made of 30HGSA steel, 200 $\mathrm{mm}$ in diameter, surfacing modes: $\mathrm{I}=170-250 \mathrm{~A}, \mathrm{U}=15-18 \mathrm{~V}$. For surfacing used welding equipment KEMPPI FastMig MXF65. Before overlaying, the parts were preheated (up to $300{ }^{\circ} \mathrm{C}$ ), to prevent the formation of cold cracks, and after overlaying, tempering was performed at a temperature of $250{ }^{\circ} \mathrm{C}$ with cooling in an oven.

The research plan was to analyze the changes in the acoustic characteristics of the deposited layer, the deposited layer after the EGT, the deposited layer after the quenching, the deposited layer after the combined exposure to quenching and the EAH.

As the filler material for the EAH, a tungsten electrode was used in direct polarity, the protective gas was argon, the coolant was water, the EGT step was $1 \mathrm{~mm}$ (Fig. 1). The EGS mode is presented in Table 1 . The initial deposited layer was quenched at $\mathrm{T}=880-900{ }^{\circ} \mathrm{C}$ for 120 minutes with oil cooling.

Table 1. Mode of EAH

\begin{tabular}{|c|c|c|c|c|c|}
\hline Current, A & $\begin{array}{c}\text { Currentdensity, } \\
\mathrm{A} / \mathrm{mm}^{2}\end{array}$ & $\begin{array}{c}\text { Arcvoltage, } \\
\mathrm{V}\end{array}$ & $\begin{array}{c}\text { Heatinput, } \\
\mathrm{kj} / \mathrm{mm}\end{array}$ & $\begin{array}{c}\text { Part rotation } \\
\text { speed, } \mathrm{m} / \mathrm{s}\end{array}$ & $\begin{array}{c}\text { Electrode } \\
\text { grinding } \\
\text { angle, }\end{array}$ \\
\hline $70-80$ & 22.3 & $22.5-22.8$ & 0.03 & 0.02 & 60 \\
\hline
\end{tabular}




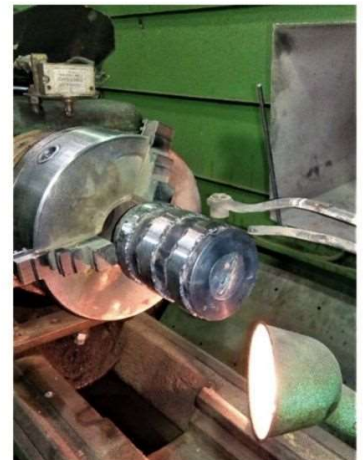

a)

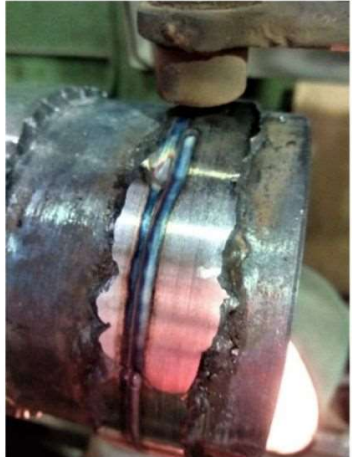

b)

Fig. 1. Carrying out the EAH: a - installation of the sample in the cartridge of the machine,- sample surface after hardening.

\section{Experimental Techniques}

To identify areas with a modified structure, as well as the degree of its change, we used spectral-acoustic analysis, with the automated acoustic system ASTRON, measurements were performed along a circle at 8 points at the same distance.

\section{Results and its discussion}

Analysis of changes in acoustic characteristics and measurements were performed on samples before and after electric arc heat hardening, along a hardened surface at eight points around the circumference.

For sample 2, an increase in the delay time of the SAW signal by 4 ns after performing the EAH is observed. After quenching, an increase of $91 \mathrm{~ns}$ occurs, then rises by $96 \mathrm{~ns}$ after electric arc hardening.

Analysis of the attenuation coefficient values Fig. 2, b) and amplitude of the SAW signal (Fig. 2, c) showed that for samples 3 and 4 decrease in the attenuation coefficient and an increase in amplitude were found, whereas for samples 1 and 2, on the contrary, an increase in the attenuation coefficient and reducing amplitude. 


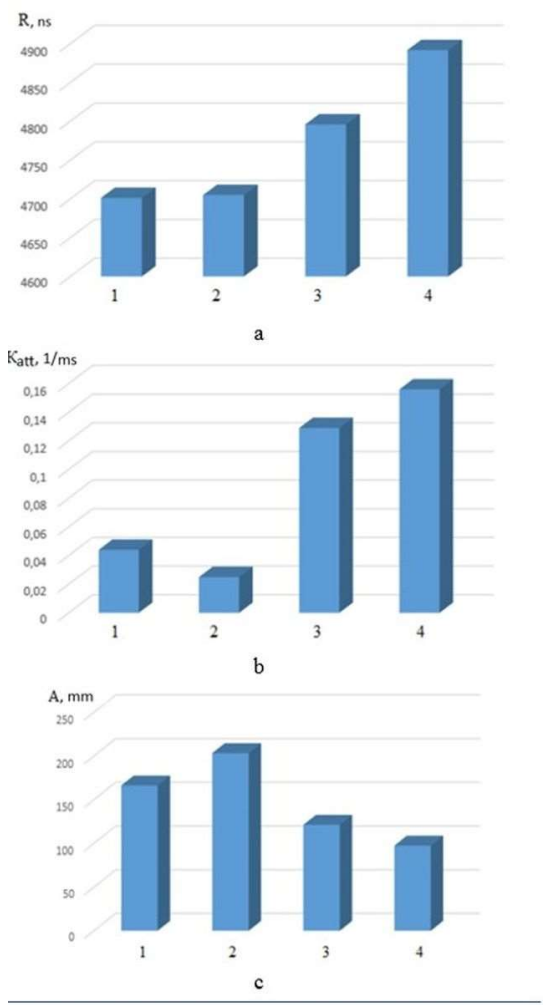

Fig. 2. Acoustic Characterization Histograms: a - delay time of the SAW signal, $R(\mathrm{~ns}) ; \mathrm{b}-$ attenuation coefficient values, $K_{\text {att }}(1 / \mathrm{ms})$; c - amplitude of the SAW signal, A (mm)

\section{Findings}

Thus, the analysis of changes in acoustic characteristics confirms the previously published research results [12].

\section{Acknowledgment}

The work was done with the financial support of the Fund for the Promotion of Innovation, contract number $12838 \mathrm{GU} / 2018$

\section{References}

1. Zh.Ying-chun, K.Yukimura, D.Chuan-xian, Zh. Ping-yuThin Solid Films, 388:1-2, 277 (2001)

2. Wu P., Du H.M., Chen X.L., Li Z.Q., Bai H.L., Jiang E.Y. Wear, 257:1-2, 142 (2004)

3. D.Y.Wang, K.W.Weng, C.L.Chang, W.Y.Ho Surf. Coat. Technol., 120, 622 (1999)

4. R.A.Pruemmer, Bhat T.Balakrishna, SivaK. Kumar, K.HokamotoExplosive compaction of powders and composites (Enfield, NH: Sci. Publ., 2006)

5. J.Milligan, D.W.Heard, M.BrochuAppl.Surf.Sci., 256, 4009 (2010)

6. J.-H.Wu, D.A.Rigney, M.A.Falk, J.H.Sanders Surf.Coat.Technol.,188:189, 605 (2004)

7. Q.Y.Hou, Z.Huang, J.T.Wang Surf.Coat.Technol., 206, 2806 (2011) 
8. U.Reisgen, L.Stein, B.Balashov. Materialwissenschaft und Werkstofftechnik, 40, 618 (2009)

9. T. Haubold, R. Birringer, B. Lengeler, H. Gleiter Phys. Lett. 135, 461 (1989)

10. B.S. Murty, M.K. Datta, S.K. PabiSadhana. 28, 23 (2003)

11. P. Keblinski, S. R. Phillpot, D. Wolf, H.GleiterJ. Eur. Ceram. Soc. 80. 717 (1997)

12. S. Veprek, S. A. ReiprichThin Solid Films., 268, 64 (1995)

13. D. V. Shtansky, E. A. Levashov, A. N. Sheveiko, J. J. MooreFilms Metallurgical and Materials Transaction. 30A, 2439 (1999)

14. N. V. Ababkov, A. N. Smirnov, E.E.Levashova,Pimonov M.V.Materials Science Forum, 938, 7 (2018)

15. A.Smirnov, N.Ababkov, A.Glinka Advanced Materials Research. 1013, 170 (2014) 